\section{Influence of Different Decontamination Approaches on Bone Substitute Adhesion to Peri-Implantitis Affected Implant Surfaces: An SEM Proof of Principle Study}

\section{Ahmed Y. Gamal, ${ }^{A, B}$ Khaled A. Abdel-Ghaffar, ${ }^{A}$ Mohamed El-Mofty, ${ }^{A, B}$ Mahmoud T. Al Destawy, ${ }^{C}$ Scott H. Froum ${ }^{D}$}

ADepartment of Periodontology, Faculty of Dental Medicine, Ain Shams University, Cairo, Egypt.

BDepartment of Periodontology, Faculty of Dental Medicine, Nahda University, Beni Suef, Egypt.

CDepartment of Periodontology, Faculty of Dental Medicine, Al Azhar University, Cairo, Egypt.

DDepartment of Periodontics, Stony Brook University School of Dental Medicine, Stony Brook, NY, USA.

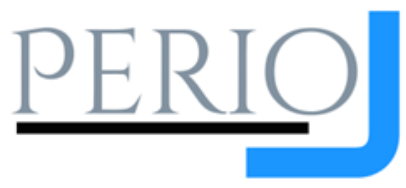

Accepted for publication: November 03, 2020

\begin{abstract}
Background: During healing, clot blended graft materials may retract away from implant surfaces creating microgaps that compromise re-osseointegration. The present study aimed to evaluate different surface decontamination materials' effect on adhesion of the graft materials to peri-implantitis affected parts, a factor that can resist clot blended graft retraction improving reosseointegration. Methods: Eighteen peri-implantitis affected implants diagnosed as hopeless and designated for removal contributed in this prospective, masked trial. Samples were randomly distributed into three groups, each of six implants. Group one (G1) was coated with hydroxyapatite of a micro particle size of 250 to $1000 \mu \mathrm{m}$ after saline surface decontamination for two minutes. Group two (G2) peri-implantitis affected parts were treated with the graft material following two minutes of chlorhexidine gluconate $0.12 \%(\mathrm{CHX})$ surface treatment. Group three (G3) implants were coated with the graft material after citric acid $(C A)(\mathrm{pH}=1)$ surface conditioning for two minutes. Implants in all groups were agitated in phosphate-buffered saline (PBS) by using an automatic tissue processor agitator for three minutes. Implants were prepared for surface scanning evaluation. Results: Scanning electron microscopy (SEM) observation of G1 saline treated control implants were devoid of bone particles adherent to peri-implantitis affected surfaces. The surface area covered by grafted particles in G2 was statistically higher than that of $\mathrm{G} 1(\mathrm{P}<0.01)$. Group three (CA-treated) showed nearly complete coverage of periimplantitis affected parts by the graft material covering $88.8 \%$ of examined surface areas which was statistically higher than that of $G 2(P<0.05)$. Conclusion: Citric acid implant surface conditioning could improve implant re-osseointegration through enhancement of the graft adhesion to the implant surface. Smear layer barrier effect seemed to be the most important factor that compromised graft adhesion to preri-implantitis affected parts of the implant surfaces.
\end{abstract}

Keywords: Peri-implantitis; bone grafts; dental implants; bone substitutes; regeneration; osseointegration; citric acid

\section{Introduction}

The screw-shaped design of implants, combined with various surface modifications of titanium limit the effect of mechanical debridement and can certainly result in incomplete removal of all adhering microorganisms. ${ }^{1}$ Association studies have 
identified a microbiota characterized by high counts and proportions of gramnegative anaerobic bacteria around implants with clinical signs of periimplantitis. ${ }^{2-6}$ Various non-surgical and surgical modalities have been tested alone or in combinations in animals, humans, or both with no definitive gold standard. ${ }^{7-9}$ Numerous methods for implant surface decontamination have been suggested as a part of non-surgical treatment. Mechanical, sonic and ultrasonic scaling, air-powder abrasion, lasers, and numerous chemical solutions such as chlorhexidine digluconate, hydrogen peroxide, citric acid (CA), and saline have been tested. ${ }^{10-13}$ Some studies indicated that all methods of surface debridement achieve resolution of the inflammatory lesion, but fail to achieve significant re-osseointegration adjacent to the peri-implantitis affected implant surface. ${ }^{14,15}$ Most animal studies demonstrated a connective tissue capsule separating implant surfaces from the adjacent bone, except at the deepest part of the defects. ${ }^{16-21}$ Mechanical therapy in adjunction to local antimicrobials reported improvements in bleeding on probing (BOP) and probing depths (PD); however, no degree of re-osseointegration has been reported. ${ }^{22,23}$

Several attempts have been made to promote re-osseointegration using regenerative techniques. In most studies, greater re-osseointegration has been observed when using a grafting material with or without resorbable or nonresorbable membranes, compared with surgical access decontamination and closed healing alone. ${ }^{24,25}$ Findings from studies that evaluated the adjunctive effect of barrier membranes have been contradictory. ${ }^{10,17,24,25}$ Most studies indicated that concept as a predictable treatment for osseous defects in periimplantitis with an improvement in soft tissue conditions; however, membranes exposure was a frequent complication. ${ }^{24}$ Although such a regenerative approach may gain considerable bone fill, reosseointegration was limited and unpredictable as reported in many studies compared to debridement alone. ${ }^{26-28}$ In addition, osseointegration cannot be determined histologically if it actually occurred in the augmented site with apparently formed dense bone at the implant's neck. ${ }^{29}$

The shrinkage of clot-blended graft material away from the implant surface is one of the most important factors that must be controlled to optimize the treatment outcomes following the use of regenerative materials. This permits recontamination of the exposed implant surface and epithelial attachment apical migration through the micro-gap that could ultimately appear between the clot-blended bone substitutes and the implant surface. ${ }^{30}$ The osteogenic cells' migration through the clot matrix causes further fibrin strand contraction in the clot matrix, which may lead to detachment of the strands from the implant thereby disrupting or stopping contact osteogenesis and osteoconduction. ${ }^{30}$ The fibroblasts' migration has been recognized as being responsible for wound contraction. ${ }^{31}$ Consequently, optimization of the adhesion and adsorption of the fibrin clot to the gingival flap and implant compromised surfaces is essential. ${ }^{32}$ Gamal reported that the exposure of a roughened dentinal tubule by ethylenediaminetetraacetic acid (EDTA) root surface etching enhanced clot blended $\beta$-tricalcium phosphate graft adhesion to periodontally affected root surfaces. He also reported that the infected smear layer removal and dentinal tubules exposure enhanced graft adhesion through the mechanical impaction of the small-sized $\beta$ tricalcium phosphate within the EDTAexposed tubules. ${ }^{33}$ Similarly, Gamal et al. claimed that exposure of the roughened implant surface by acid treatment enhanced mechanical integration of nanohydroxyapatite (NHA) particles onto periimplantitis affected surfaces, which could enhance re-osseointegration. ${ }^{34}$ To the best of our knowledge, the effect of various decontamination materials on graft adsorption and adhesion to peri-implantitis affected surfaces has not been clarified. In the present scanning electron microscopy (SEM) study, the hypothesis to be tested is that implant surface decontamination is the 
main factor that determines the adhesion of graft particles to the surface. Implant surface topography following debridement and etching with $\mathrm{CA}$, chlorhexidine gluconate $0.12 \%(\mathrm{CHX})$, or saline solution and the adhesion power of micro-sized biphasic calcium phosphate (BCP) bioceramics to treated peri-implantitis affected implant surfaces were evaluated.

\section{Materials and Methods}

\section{Sample Selection and Assignment}

Eighteen peri-implantitis affected implants diagnosed as hopeless and designated for removal were collected for this prospective study, masked, in vitro trial from patients seeking care for peri-implantitis at the Departments of Periodontology, Faculty of Oral and Dental Medicine, Ain-Shams University, Cairo, Egypt. Recruited patients were non-smokers with stage 3 and 4 , grade B periodontitis. ${ }^{35}$ Patients participating in this trial were 26 to 47 years of age at the time of baseline examination (mean age: $33 \pm 8.1$ years). Each patient contributed a single implant from the anterior or premolar maxillary or mandibular areas. Intraoral radiographs of implants showed marginal bone loss of $\geq 4$ threads and PD $\geq 6 \mathrm{~mm}$, $\mathrm{BOP}$, and suppuration from the pockets.

\section{Experimental Protocol}

Prior to the removal of peri-implantitis affected implants, a size 0 round bur was used to mark the affected parts under copious water irrigation. After removing the implants, adherent blood and saliva were removed by physiologic saline solution. Each implant was placed in an individual sterile container and stored at $0^{\circ} \mathrm{C}$ to $5^{\circ} \mathrm{C}$ until initiation of the experiment. At the time of sample procurement, the peri-implantitis affected parts received thorough debridement using hand titanium curettes. ${ }^{\text {a }}$ Samples were randomly distributed using coin toss (coin was flipped by the same individual, Dr. MTD, Al Azhar University, Cairo, Egypt, who was not involved in any

\footnotetext{
a Barnhart Universal Curettes, Dental A2Z Limited, UK

b MetaBiomed, DM bone, Korea

c Hexitol, The Arab Drug Company ADCD, Egypt

d Regional Center of Mycology and Biotechnology, Cairo, Egypt
}

aspect of the study) according to surface treatment into three groups each of six implants. Peri-implantitis affected parts in group 1 (G1) were treated with BCP bioceramics of a microparticle size 250 to $1000 \mu \mathrm{m}^{\mathrm{b}}$ following saline surface decontamination for 2 minutes. Group 2 (G2) peri-implantitis affected parts were treated with the same graft material following two minutes of $\mathrm{CHX}{ }^{c}$ surface treatment. Group 3 (G3) implants were treated with the graft material after two minutes of surface conditioning using $\mathrm{CA}(\mathrm{pH}=1) .{ }^{\mathrm{d}}$ Implants, including surface coating, in all groups were agitated in phosphate-buffered saline (PBS) by using an automatic tissue processor agitatore for three minutes at speed number one.

\section{SEM Preparation}

After completing the experimental procedures, all implants were mounted on aluminum stubs covered with colloidal graphite then sputter-coated with a thin layer of gold-palladium $\left(200 \mathrm{~A}^{\circ}\right)$, and stored at room temperature. Scanning electron microscopy observations and records were performed by a masked operator (AG) using a scanning electron microscope ${ }^{f}$ at $5.0 \mathrm{kV}$. The samples were dried overnight in a dehydration jar before mounting on the aluminum stubs. Representative SEM photomicrographs for each test area at different magnification levels were produced. An image analysis system ${ }^{9}$ was used to measure the implant surface area occupied by adherent graft particles. A 0.02 $\mathrm{mm}$ circular region of interest was used to trace the representative area as a means of standardization of the measurement method at a magnification of 500 . Other photomicrographs were taken at higher magnifications to identify the nature of the deposited materials. Data were presented as mean and standard deviation (SD) values.

\section{$\underline{\text { Results }}$}

\footnotetext{
e Leica EM TP, Leica Microsystems, Vienna, Austria

† JEOL JSM-1600, JEOL USA, Peabody, MA

g Able Image Analyser, Version 3.6 Self-Installer, Mu Labs, Ljubljana, Slovenia
} 
The present study included seven implants that were sand-blasted and large grit- and acid-etched; six were grit-blasted and high temperature etched implants; and five were plasma sprayed implants. Table 1 shows the percentage of surface areas covered by the graft material in all groups.

Table 1. Mean values, standard deviation (SD) values, and results of analysis of variance test for comparison among graft particle coverage percentage in different groups

\begin{tabular}{|c|c|c|c|c|}
\hline \multicolumn{5}{c}{ Percentage of Coverage } \\
\hline Group & Mean & SD & Significance & $\begin{array}{c}P \\
\text { Value }\end{array}$ \\
\hline G1 & 2.6 & 17.7 & A & $<0.001$ \\
\hline G2 & 48.5 & 7.8 & B & \\
\hline G3 & 88.8 & 6.7 & C \\
\hline
\end{tabular}

*Significant at $\mathrm{P}<0.05$; mean values with different letters are statistically, significantly different according to the Tukey test.

Scanning electron microscopy observation of $\mathrm{G} 1$ saline treated control implants were found mostly devoid of bone particles adherent to the peri-implantitis affected surfaces. All surfaces showed an amorphous, irregular surface of smear coating that completely obscured the implant surface pore orifices. All specimens showed areas of plaque and partially detached debris on the implant surfaces (Figures 1,2). One sample showed monolayered graft particle adhesion covering small areas ( $17.7 \%$ of the surface examined).

\section{Figure 1.}

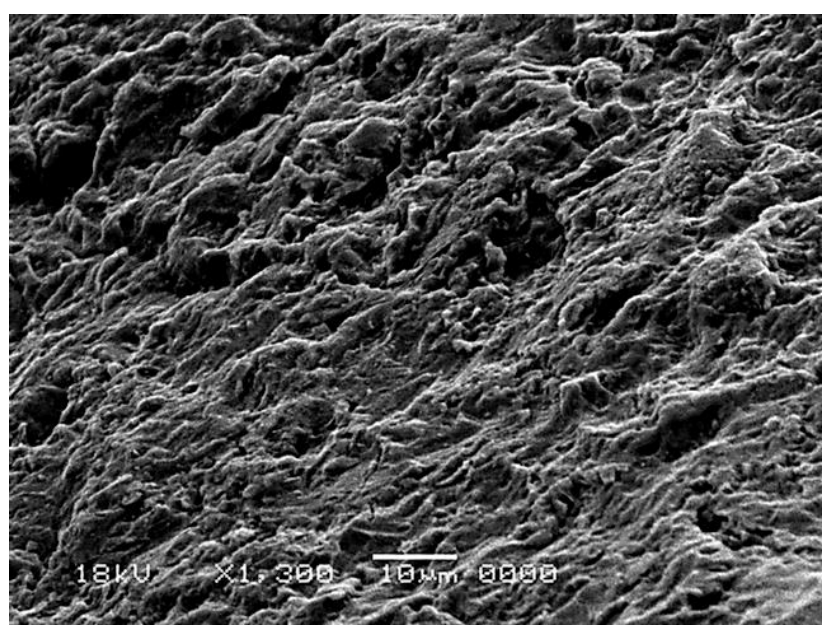

A homogenous smear layer is covering the entire surface with no graft adherent to the surface of a G1 saline treated sample. Note the total obliteration of the implant surface topography.
Figure 2.

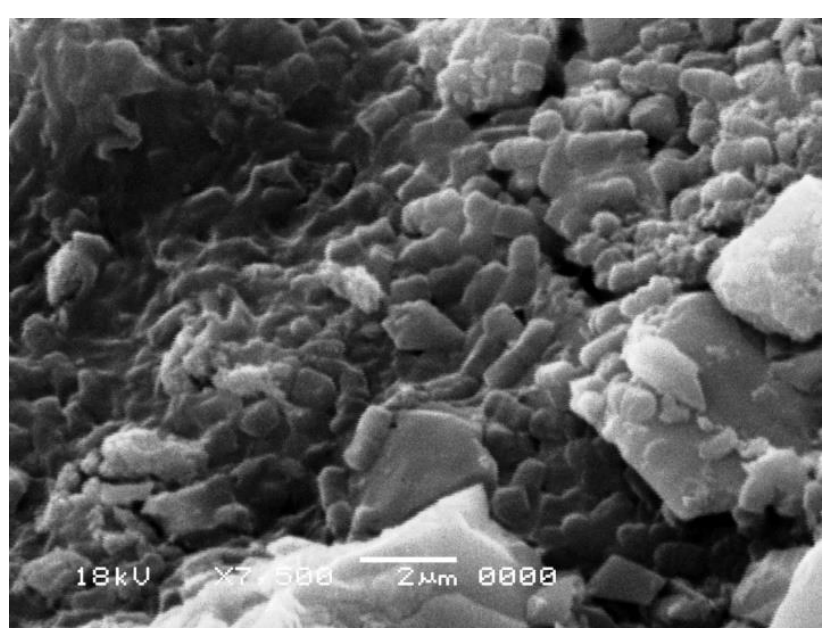

Mature biofilm consisting of multiple layers of rods and coccoid bacteria covering some parts of $\mathrm{G} 1$ samples indicating the limited antibacterial effect of saline irrigation

At this particular site the surface appeared uncovered by the surrounding surface smear layer. Group 2 ( $\mathrm{CHX}$ treated implants) showed areas of bone substitute adhesion to the peri-implantitis affected parts (48.5\%) in four samples. The surface in between the adherent particles appeared relatively clean with no smear coating (Figure 3). Two samples revealed total smear coverage devoid of graft material-implant surface adhesion. A porous smear coating was a common finding in all samples of the $\mathrm{CHX}$ group (Figure 4). Bacterial colonization was also evident in all samples. The surface area that was covered by grafted particles was statistically higher than that of $\mathrm{G} 1(\mathrm{P}<0.05)$. Group 3 (CA-treated) revealed significant coating of the peri-implantitis affected parts by the grafted material covering $88.8 \%$ of the surface areas examined (Figure 3).

\section{Figure 3.}

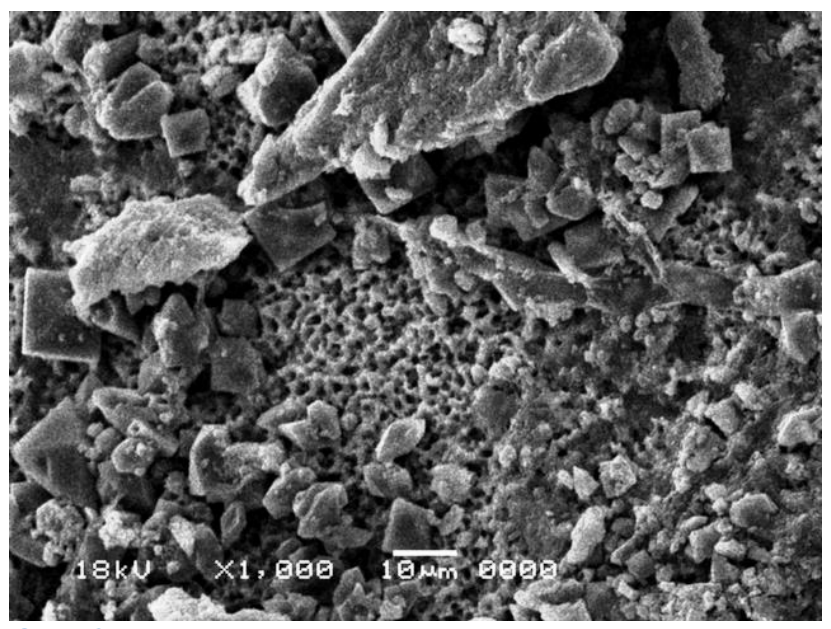

G2 CHX treated sample with single layered separated particles adherent to a clean smear uncovered area of the implant surface 


\section{Figure 4.}

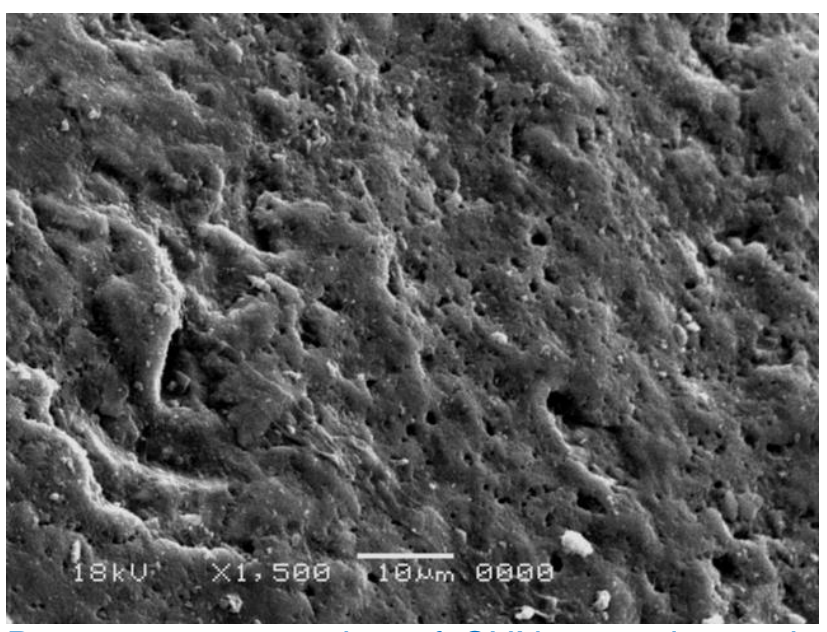

Porous smear coating of $\mathrm{CHX}$ treated sample suggesting creation of substantive $\mathrm{CHX}$ mechanical barrier preventing graft adhesion

No samples appeared devoid of the graft material that was packed in a multilayered pattern (Figure 5). The impactions of graft material within the exposed pores of implant surfaces were evident in most samples. The large particles appeared to be coated with plenty of adsorbed smaller graft particles (Figure 6). The implant surfaces appeared without smear layer surface coverage with a detectable exposure of implant surface micro-textured orifices (Figure 7). No bacterial accumulations were observed on any of the samples examined. Citric acid etching did not appear to damage titanium implant surfaces and no morphologic changes were observed in any of the examined samples (Figure 7). The surface area coated by grafted particles was found to be statistically higher than that of $\mathrm{G} 1$ and $\mathrm{G} 2(\mathrm{P} \leq 0.05)$.

\section{Figure 5.}

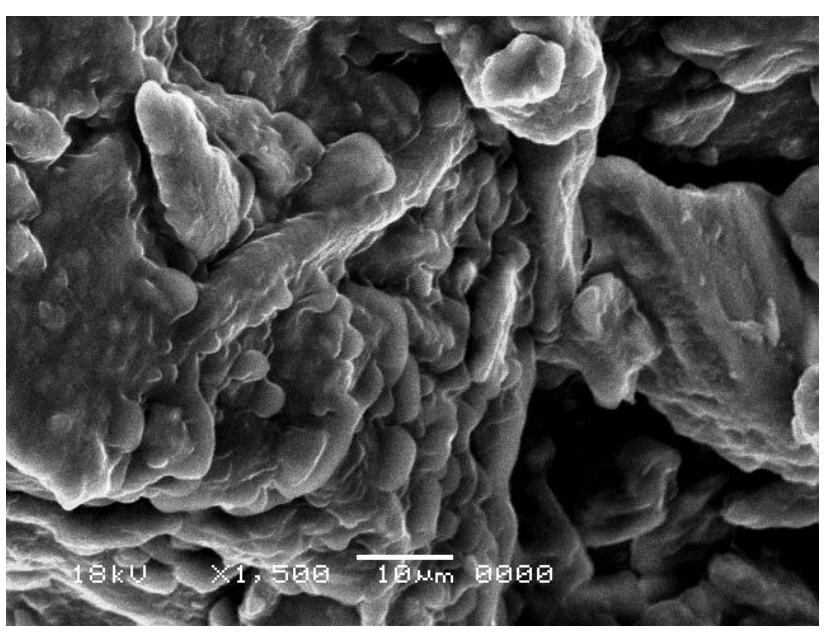

G3 treated samples showed multilayered graft adhesion to the implant surface
Figure 6.

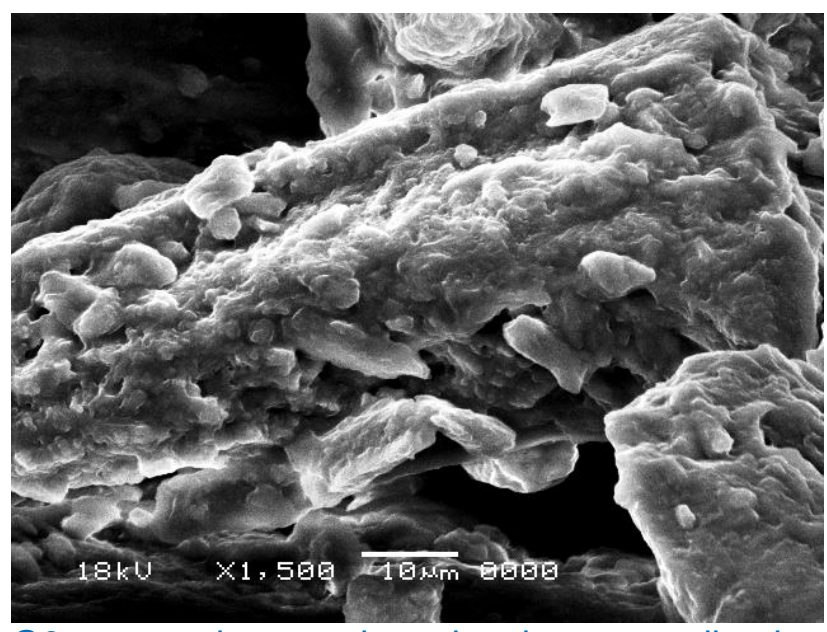

G3 treated sample showing co-adhesion between small graft particles and larger particles in a multilayered pattern

\section{Figure 7.}

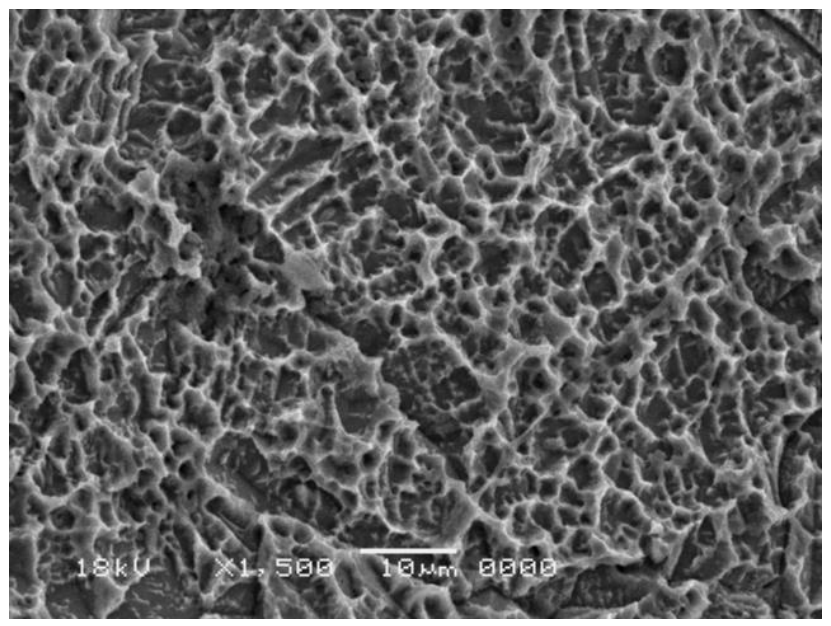

G3 citric acid treated sample showing clean rough implant surface area

\section{Discussion}

Peri-implantitis affected parts are usually covered with an infected smear layer of instrumentation debris after routine implant preparation, which seems to compromise adhesion of the fibrin clot to such altered surfaces. ${ }^{34}$ In addition, the continuous mobility of the flap and early clot retraction could move the clot-blended graft complex away from the implant surface which subsequently induces a microgap, graft epithelialization, and eventual recontamination of the implant surface.$^{30}$ For that reason, treating peri-implantitis affected implant surfaces should include complete infected biofilm and smear-like layer removal with a resultant complete exposure of the roughened titanium implant surfaces. In the present study, the authors hypothesized that the most important factor that could enhance graft adhesion to peri-implantitis affected surfaces is the implant surface etchant type. They selected to detoxify and clean the 
implant surfaces with saline, $\mathrm{CHX}$, and $\mathrm{CA}$ because they appeared safer with regard to their effect on clot stability in comparison to EDTA. ${ }^{36}$ The current study includes the more challenging failed implants in patients treated for periodontitis. An association between periodontal and peri-implant conditions has been reported. In individuals with a history of periodontitis, the incidence of peri-implantitis was reported to be four to five times higher than in individuals with no history of periodontitis. ${ }^{37}$ Thus, individuals who are susceptible to periodontitis may show increased implant marginal bone loss. ${ }^{38}$ Many authors have published articles using tetracycline and $C A$ as detoxifying agents with successful results. ${ }^{39-41}$ However, due to inadequate defect isolation, dental plaque reformed within seconds following chemical surface treatment, resulting in a rapid recontamination of the implant surfaces and subsequent long junctional epithelial healing. ${ }^{42}$ Therefore, in this study, the authors immediately applied hydroxyapatite-grafted particles onto chemically detoxified implant surfaces in order to determine which detoxifying agent could optimize graft-implant integration which is supposed to prevent the recontamination of the implant surfaces. Citric acid surface treatment was associated with the highest percentage of adherent graft material to implant surface compared to that of saline and $\mathrm{CHX}$. The immediate graft application and the effective antibacterial and smear removal capacity of CA which was seen in all examined samples seemed to be responsible for such enhanced graftimplant adhesion. The chemical treatment of the implant surface and the exposure of implant surface pores were found to be important for enhancing re-osseointegration. Cooper reported that an increase in titanium implants' surface roughness improved bone integration with respect to the amount of bone formed at the interface and increased osteoconduction, and osteogenesis. ${ }^{43}$ Citric acid has been shown to reduce Porphyromonas gingivalis and Escherichia coli lipopolysaccharides when applied for two minutes in vitro. ${ }^{44,45}$ Citric acid appeared to be safe and no surface alterations were seen on any of the examined samples. In the present study, the use of plastic curettes to clean the implant surface appeared to maintain the integrity of the implant surface topography. It has been shown that the use of metallic curettes alter the implant surface favoring bacterial colonization, while plastic curettes induce minimal damage or none at all. ${ }^{46}$ Contrary to what was found in our study, Frank MJ et al. reported that low $\mathrm{pH}$ acidic substances like $\mathrm{CA}$ have been related to implant surface corrosion, potentially reducing the chance for reosseointegration. ${ }^{47} \mathrm{~A}$ recent systematic review reported that $40 \% \mathrm{CA}$ of $\mathrm{pH} 1$ for 30 60 seconds proved to be the most effective agent for bacterial growth reduction on hydroxyapatite surfaces, although periimplant tissues could be affected by the clinical application at a more acidic $\mathrm{pH}$ and the prolonged time of application can affect the union between the hydroxyapatite and the implant body. The multilayered particle adhesion seen in most of the samples treated with CA could reflect an acceptable implant surface energy that favors graft consolidation. The enhanced smear removal capacity appeared to improve initial wettability and to retain sandblasted and acid-etched (SLA) implant microstructure, both of which could be important in inducing multilayered graft adhesion to the implant surface. Initial adhesion begins in areas of high wettability (a characteristic of titanium) and inside the pits and grooves of the roughened surfaces, where it is difficult to eliminate. ${ }^{48}$

The smear coating in the $\mathrm{CHX}$ group appeared different from that of the saline treated group. In contrast to the homogeneous saline treated smear layer, the $\mathrm{CHX}$ smear surface appeared disintegrated and porous suggesting a lack of smear removal power of the saline solution and a certain degree of limited smear removal capacity of CHX. Chlorhexidine seepage within the implant surface pores with subsequent adsorption to its internal surfaces could explain the porous appearance of $\mathrm{CHX}$ smear layer. Unexpectedly, CHX showed significantly lower levels of graft adhesion compared to that of CA. The limited smear removal capacity and the creation of a porous $\mathrm{CHX}$ smear coating could be an explanation for 
such limited graft adhesion. The substantive $\mathrm{CHX}$ layer could act as a barrier, explaining the reduced graft-implant adhesion power. In contrast to CA which could be completely washed away following the two-minute application, $\mathrm{CHX}$ is adsorbed to implant surfaces creating a smear layer which could possibly form a mechanical and biological barrier compromising graft adhesion. Many areas of bacterial colonies covering the surface of $\mathrm{CHX}$ treated samples were evident. This could be the result of the biofilms being protected by a characteristic glycocalix or the fact that limited mechanical disruption and $\mathrm{CHX}$ diffusion occurred at the inaccessible rough areas. Chlorhexidine has been seen to be ineffective on hydroxyapatite surfaces for bacterial growth reduction. ${ }^{48}$ On the other hand, a review by Claffey et al. of 43 experimental and clinical studies which evaluated different decontamination protocols using sterile saline solution, $\mathrm{CA}, \mathrm{CHX}$, and hydrogen peroxide, failed to show that any one method was more effective than the others. ${ }^{49}$

In spite of the fact that many studies reported a clinical improvement following saline irrigation of peri-implantitis affected surfaces, the implant surfaces that were saline treated appeared in the present study completely covered by a smear layer which could explain the nearly total lack of graft particles over the implant surfaces. Our same group's previous study suggested a smear layer being a major barrier compromising the adhesion of grafted particles to implant surfaces. ${ }^{34}$ Similarly, Gamal reported that the smear layer compromised the adhesion of graft material to periodontally affected root surfaces. ${ }^{33}$ Human studies have shown that implant surface cleaning combined with mechanical methods, such as curettes and saline soaked cotton pellets, contribute to obtain clinically stable results for up to 24 months. ${ }^{50,51}$ An anti-infective therapy including surgical debridement of implant surfaces with carbon fiber curettes or titanium covered curettes, followed by rubbing of the implant surface with sterile saline soaked gauze and rinsing with saline, as well as post-operative prescription of amoxicillin and metronidazole for 7 days were found to prevent the disease's progression for 12 months. ${ }^{52}$ Saline irrigation in the present study was found to remove surface debris following mechanical debridement but not the firmly adherent smear layer on rough implant surfaces. Following periodontal healing scenarios, root surface debridement and graft application without smear removal usually resulted in improved clinical parameters in spite of the reduced adhesion of the clot blended graft to the smear covered root surface which compromises true regeneration. Similarly, implant surface debridement followed by saline irrigation with its limited smear removal capacity could improve clinical parameters in spite of the compromised graft-implant adhesion. Such lack of union between the grafted particles and instrumented implant surfaces cannot prevent the apical migration of the epithelial attachment, which is the major cause of partial or complete exfoliation of bone particles with the resultant implant surface being nonconductive for bone formation. ${ }^{10}$, 24,25 It has been suggested that the provision of an implant surface conductive to bone formation is a prerequisite for successful regenerative treatment of peri-implantitis. ${ }^{16}$ The present finding contradicts that of Persson et al. who reported that the use of saline soaked cotton pellets to treat induced peri-implantitis in dogs in combination with systemic amoxicillin and metronidazole for 17 days resulted in re-osseointegration of smooth surfaced implants and SLA surfaced implants, with significantly more osseointegration in SLA implants. ${ }^{53}$

Within the limitations of this study, the authors can conclude that the use of CA conditioning for titanium implants improves the adhesion of the graft to peri-implantitis affected surfaces. Chlorhexidine and saline surface conditioning appeared to be an ineffective means of surface treatment. The effect of CA surface treatment resulting in organic smear removal and titanium pore exposure improves such integration. Such improved adhesion seems to retard the apical migration of the epithelial attachment that could enhance re-osseointegration.

\section{Acknowledgements:}


The authors thank Dr. Khaled Kerra of the Faculty of Dentistry, Misr International University, Cairo, Egypt, for performing the statistical analysis of data. This work was partially supported by Ain Shams University, Cairo, Egypt.

\section{References}

1. Gosau M, Hahnel S, Schwarz F, Gerlach $T$, Reichert TE, Bürgers R. Effect of six different peri-implantitis disinfection methods on in vivo human oral biofilm. Clin Oral Implants Res. 2010 Aug; 21(8):866-72.

https://doi.org/10.1111/j.1600-

0501.2009.01908.x

2. Adell R, Lekholm U, Rockler $B$, et al. Marginal tissue reactions at osseointegrated titanium fixtures (I). A 3year longitudinal prospective study. Int $J$ Oral Maxillofac Implants Surg. 1986 Feb; 15(1):39-52.

https://doi.org/10.1016/s0300-

9785(86)80010-2

3. Lindhe J, Berglundh T, Ericsson I, Liljenberg B, Marinello C. Experimental breakdown of peri-implant and periodontal tissues. A study in the beagle dog. Clin Oral Implants Res. 1992 Mar; 3(1):9-16. https://doi.org/10.1034/j.16000501.1992.030102.x

4. Mombelli A, van Oosten MA, Schurch Jr E, Land NP. The microbiota associated with successful or failing osseointegrated titanium implants. Oral Microbiol Immunol. 1987 Dec; 2(4):14551. https://doi.org/10.1111/j.1399302x.1987.tb00298.x

5. Shibli JA, Melo L, Ferrari DS, Figueiredo LC, Faveri M, Feres M. Composition of supra- and subgingival biofilm of subjects with healthy and diseased implants. Clin Oral Implants Res. 2008 Oct; 19(10):975-82. https://doi.org/10.1111/j.16000501.2008.01566.x

6. Tabanella G, Nowzari H, Slots J. Clinical and microbiological determinants of ailing dental implants. Clin Implant Dent Relat Res. 2009 Mar; 11(1):24-36. https://doi.org/10.1111/j.17088208.2008.00088.x
7. Rosenberg ES, Cho SC, Elian N, Jalbout ZN, Froum S, Evian Cl. A comparison of characteristics of implant failure and survival in periodontally compromised and periodontally healthy patients: a clinical report. Int J Oral Maxillofac Implants. Nov-Dec 2004; 19(6):873-9.

8. O'Mahony A, Spencer P. Osseointegrated implant failures. $\mathrm{J} / r$ Dent Assoc. 1999; 45(2):44-51.

9. Berglundh T, Persson L, Klinge B. A systematic review of the incidence of biological and technical complications in implant dentistry reported in prospective longitudinal studies of at least 5 years. $J$ Clin Periodontol. 2002; 29 Suppl 3:197212; discussion 232-3. https://doi.org/10.1034/j.1600-

051x.29.s3.12.x 10.1034/j.1600051x.29.s3.12.x

10. Schou S, Holmstrup P, Jørgensen T, et al. Implant surface preparation in the surgical treatment of experimental periimplantitis with autogenous bone graft and ePTFE membrane in cynomolgus monkeys. Clin Oral Implants Res. 2003 Aug; 14(4):412-22. https://doi.org/10.1034/j.16000501.2003.00912.x

11. Sato S, Kishida M, Ito $K$. The comparative effect of ultrasonic scalers on titanium surfaces: an in vitro study. $J$ Periodontol. 2004 Sep; 75(9):1269-73. https://doi.org/10.1902/jop.2004.75.9.12 69

12. Schwarz F, Sculean A, Romanos G, et al. Influence of different treatment approaches on the removal of early plaque biofilms and the viability of SAOS2 osteoblasts grown on titanium implants. Clin Oral Investig. 2005 Jun; 9(2):111-7.

https://doi.org/10.1007/s00784-0050305-8

13. Karring ES, Stavropoulos A, Ellegaard $B$, Karring T. Treatment of periimplantitis by the Vector system. Clin Oral Implants Res. 2005 Jun; 16(3):28893. https://doi.org/10.1111/j.16000501.2005.01141.x

14. Matarasso S, Quaremba G, Coraggio F, Vaia E, Cafiero C, Lang NP. Maintenance of implants: an in vitro study of titanium implant surface 
modifications subsequent to the application of different prophylaxis procedures. Clin Oral Implants Res. 1996 Mar; 7(1):64-72. https://doi.org/10.1034/j.1600-

0501.1996.070108.x

15. McCollum J, O'Neal RB, Brennan WA, Van Dyke TE, Horner JA. The Effect of Titanium Implant Abutment Surface Irregularities on Plaque Accumulation In Vivo. J Periodontol. 1992 Oct; 63(10):802-5.

https://doi.org/10.1902/jop.1992.63.10.8 02

16. Schwarz F, Jepsen S, Herten M, Sager $M$, Rothamel D, Becker J. Influence of different treatment approaches on nonsubmerged and submerged healing of ligature induced peri-implantitis lesions: an experimental study in dogs. J Clin Periodontol. 2006 Aug; 33(8):584-95. https://doi.org/10.1111/j.1600-

051X.2006.00956.X

17. Grunder $U$, Hürzeler $M B$, Schüpbach $P$, Strub JR. Treatment of ligature-induced peri-implantitis using guided tissue regeneration: a clinical and histologic study in the beagle dog. Int $J$ Oral Maxillofac Implants. 1993; 8(3):282-93.

18. Ericsson I, Persson LG, Berglundh T, Edlund $\mathrm{T}$, Lindhe $\mathrm{J}$. The effect of antimicrobial theram on peri-implantitis lesions. An experimental study in the dog. Clin Oral Implants Res. 1996 Dec; 7(4):320-8.

https://doi.org/10.1034/j.1600-

0501.1996.070404.x

19. Persson LG, Ericsson I, Berglundh T, Lindhe J. Guided bone regeneration in the treatment of periimplantitis. Clin Oral Implants Res. 1996 Dec; 7(4):366-72. https://doi.org/10.1034/j.16000501.1996.070410.x

20. Persson LG, Araújo MG, Berglundh T, Gröndahl K, Lindhe J. Resolution of periimplantitis following treatment. An experimental study in the dog. Clin Oral Implants Res. 1999 Jun; 10(3):195-203. https://doi.org/10.1034/j.16000501.1999.100302.x

21. Persson LG, Ericsson I, Berglundh T, Lindhe J. Osseintegration following treatment of peri-implantitis and replacement of implant components. An experimental study in the dog. $J$ Clin Periodontol. 2001 Mar; 28(3):258-63. https://doi.org/10.1034/j.1600051x.2001.028003258.x

22. Renvert $S$, Roos-Jansåker AM, Claffey $N$. Non-surgical treatment of periimplant mucositis and peri-implantitis: a literature review. J Clin Periodontol. 2008 Sep; 35(8 Suppl):305-15. https://doi.org/10.1111/j.1600051X.2008.01276.X

23. Mombelli A. Microbiology and antimicrobial therapy of peri-implantitis. Periodontol 2000. 2002; 28:177-189. https://doi.org/10.1034/j.16000757.2002.280107.x

24. Claffey N, Clarke E, Polyzois I, Renvert $\mathrm{S}$. Surgical treatment of peri-implantitis. J Clin Periodontol. 2008 Sep; 35(8 Suppl):316-32.

https://doi.org/10.1111/j.1600051X.2008.01277.x

25. Hürzeler MB, Quiñones CR, Schüpback $P$, Morrison EC, Caffesse RG. Treatment of peri-implantitis using guided bone regeneration and bone grafts, alone or in combination, in beagle dogs. Part 2: Histologic findings. Int $J$ Oral Maxillofac Implants. 1997 Mar-Apr; 12(2):168-75.

26. Machado MA, Stefani CM, Sallum EA, et al. Treatment of ligature-induced periimplantitis defects by regenerative procedures. Part II: A histometric study in dogs. J Oral Sci. 2000 Sep; 42(3):1638.

https://doi.org/10.2334/josnusd.42.163

27. Nociti FH Jr, Caffesse RG, Sallum EA, Machado MA, Stefani CM, Sallum AW. Evaluation of guided bone regeneration and/or bone grafts in the treatment of ligature-induced peri-implantitis defects: a morphometric study in dogs. J Oral Implantol. 2000; 26(4):244-9. https://doi.org/10.1563/15481336(2000)026<0244:EOGBRA>2.3.C $0 ; 2$

28. Nociti FH Jr, Machado MA, Stefani CM, Sallum EA. Absorbable versus nonabsorbable membranes and bone grafts in the treatment of ligatureinduced periimplantitis defects in dogs: a histometric investigation. Int $J$ Oral 
Maxillofac Implants. 2001 Sep-Oct; 16(5):646-52.

29. Sewerin IP, Gotfredsen K, Stoltze K. Accuracy of radiographic diagnosis of peri-implant radiolucencies--an in vitro experiment. Clin Oral Implants Res. 1997 Aug; 8(4):299-304. https://doi.org/10.1034/j.16000501.1997.080408.x

30. Davies JE. Mechanisms of endosseous integration. Int J Prosthodont. 1998 SepOct; 11(5):391-401.

31. Ehrlich HP. The role of connective tissue matrix in wound healing. In: Barbul $A$, Pines E, Caldwell M, Hunt TK, eds. Growth Factors and Other Aspects of Wound Healing: Biological and Clinical Implications. New York: Liss; 1988: 243258.

32. Baker DL, Stanley Pavlow SA, Wikesjö UME. Fibrin clot adhesion to dentin conditioned with protein constructs: an in vitro proof-of-principle study. J Clin Periodontol. 2005 Jun; 32(6):561-6. https://doi.org/10.1111/j.1600-

051X.2005.00714.x

33. Gamal AY. Enhanced B-Tricalcium Phosphate Blended Clot Adhesion to EDTA Biomodulated Periodontally Affected Root Surfaces: In Vivo Scanning Electron Microscopy Evaluation. J Periodontol. 2011 Nov; 82(11):1587-95.

https://doi.org/10.1902/jop.2011.110023

34. Gamal AY, Abdel-Ghaffar KA, lacono JV. A Novel Approach for Enhanced Nanoparticle-Sized Bone Substitute Adhesion to Chemically Treated PeriImplantitis-Affected Implant Surfaces: An In Vitro Proof-of-Principle Study. J Periodontol. 2013 Feb; 84(2):239-47. https://doi.org/10.1902/jop.2012.120023

35. Armitage GC. Development of a classification system for periodontal diseases and conditions. Ann Periodontol. 1999 Dec; 4(1):1-6. https://doi.org/10.1902/annals.1999.4.1. 1

36. Gamal AY, Mailhot JM. The effects of EDTA gel conditioning exposure time on periodontitis-affected human root surfaces: surface topography and PDL cell adhesion. J Int Acad Periodontol. 2003 Jan; 5(1):11-22.
37. Karoussis IK, Salvi GE, Heitz-Mayfield LJA, Brägger U, Hämmerle CHF, Lang NP. Long-term implant prognosis in patients with and without a history of chronic periodontitis: a 10-year prospective cohort study of the ITI Dental Implant System. Clin Oral Implants Res. 2003 Jun; 14(3):329-39. https://doi.org/10.1034/j.16000501.000.00934.x

38. Hardt CRE, Gröndahl K, Lekholm U, Wennström JL.Outcome of implant therapy in relation to experienced loss of periodontal bone support: A retrospective 5-year study. Clin Oral Implants Res. 2002 Oct; 13(5):488-94. https://doi.org/10.1034/j.16000501.2002.130507.x

39. Reiser GM, Nevins M. The implant periapical lesion: etiology, prevention, and treatment. Compend Contin Educ Dent. 1995 Aug; 16(8):768, 770, 772 passim.

40. McAllister BS, Masters D, Meffert RM. Treatment of implants demonstrating periapical radiolucencies. Pract Periodontics Aesthet Dent. 1992 NovDec; 4(9):37-41.

41. Sussman HI. Periapical implant pathology. J Oral Implantol. 1998; 24(3):133-8.

https://doi.org/10.1563/15481336(1998)024<0133:PIP>2.3.CO;2

42. Bloomquist CG, Reilly BE, Liljemark WF. Adherence, accumulation, and cell division of a natural adherent bacterial population. J Bacteriol. 1996 Feb; 178(4):1172-7.

https://doi.org/10.1128/jb.178.4.11721177.1996

43. Cooper LF. A role for surface topography in creating and maintaining bone at titanium endosseous implants. $J$ Prosthet Dent. 2000 Nov; 84(5):522-34. https://doi.org/10.1067/mpr.2000.11196 6

44. Dennison DK, Huerzeler MB, Quinones C, Caffese RG. Contaminated Implant Surfaces: An In Vitro Comparison of Implant Surface Coating and Treatment Modalities for Decontamination. $J$ Periodontol. 1994 Oct; 65(10):942-8. https://doi.org/10.1902/jop.1994.65.10.9 42 
45.Zablotsky MH, Diedrich DL, Meffert RM. Detoxification of endotoxincontaminated titanium and hydroxyapatite-coated surfaces utilizing various chemotherapeutic and mechanical modalities. Implant Dent. 1992; 1(2):154-8. https://doi.org/10.1097/00008505199205000-00009

46. Mengel R, Meer C, Flores-de-Jacoby L. The treatment of uncoated and titanium nitride-coated abutments with different instruments. Int $J$ Oral Maxillofac Implants. 2004 Mar-Apr; 19(2):232-8.

47. Frank MJ, Walter MS, Lyngstadaas SP, Wintermantel E, Haugen HJ. Hydrogen content in titanium and a titaniumzirconium alloy after acid etching. Mater Sci Eng C Mater Biol Appl. 2013 Apr; 33(3):1282-8.

https://doi.org/10.1016/j.msec.2012.12. 027

48. Mellado-Valero A, Buitrago-Vera $P$, Solá-Ruiz MF, Ferrer-García JC. Decontamination of dental implant surface in peri-implantitis treatment: a literature review. Med Oral Patol Oral Cir Bucal. Nov 2013; 18(6):e869-76. https://doi.org/10.4317/medoral.19420

49. Claffey N, Polyzois I, Ziaka P. An overview of non-surgical and surgical therapy. Periodontol 2000. 2004; 36:3544 . https://doi.org/10.1111/j.16000757.2004.00073.x

50. Schwarz F, John G, Mainusch S, Sahm $\mathrm{N}$, Becker J. Combined surgical therapy of peri-implantitis evaluating two methods of surface debridement and decontamination. A two-year clinical follow up report. J Clin Periodontol. 2012 Aug; 39(8):789-97. https://doi.org/10.1111/j.1600-

051X.2012.01867.x

51. Schwarz F, Sahm N, Becker J. Combined surgical therapy of advanced peri-implantitis lesions with concomitant soft tissue volume augmentation. A case series. Clin Oral Implants Res. 2014 Jan; 25(1):132-6.

https://doi.org/10.1111/clr.12103

52. Heitz-Mayfield LJA, Salvi GE, Mombelli A, Faddy M, Lang NP. Anti-infective surgical therapy of peri-implantitis. A 12month prospective clinical study. Clin Oral Implants Res. 2012 Feb; 23(2):205$10 . \quad$ https://doi.org/10.1111/j.16000501.2011.02276.x

53. Persson LG, Araújo MG, Berglundh T, Gröndahl K, Lindhe J. Resolution of periimplantitis following treatment. An experimental study in the dog. Clin Oral Implants Res. 1999 Jun; 10(3):195-203. https://doi.org/10.1034/j.16000501.1999.100302.x

Conflicts of interest: The authors declared no conflicts of interest related to this work.

\section{Corresponding author:}

\section{Dr. Ahmed Y. Gamal}

Professor and Chair, Department of

Periodontology

Faculty of Dental Medicine

Ain Shams University

Cairo, Egypt

E-mail: hgamal1@hotmail.com

Phone: +20 1006607176

This is an open access article distributed under the Creative Commons AttributionNoncommercial-NoDerivatives 4.0 International (CC BY-NC-ND 4.0) License. 